\title{
The law, the environment and the mosquito
}

\author{
by Martin Polden
}

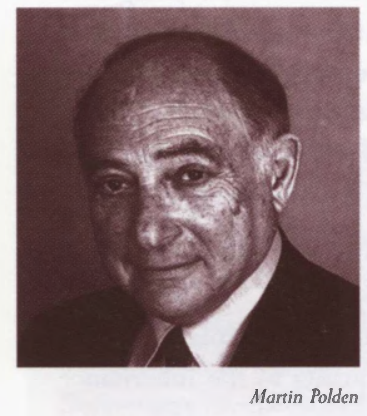

$\mathrm{I}$ n selecting my title I am indebted to Professor Wolfgang Sachs of the Wuppertal Institute for Climate, Energy and Environment and his contribution to the 1999 Schumacher Lectures. These lectures are an annual feature of the Schumacher Society, established in the memory and spirit of Dr Fritz Schumacher, whose book, Small is Beautiful, published in the early '70s, proved to be the precursor of much modern environmental thinking and whose inspiration survives through the society's work.

I emphasise this connection, since it is part of my argument that the law, and those who make and practice the law, cannot approach environmental issues in isolation - as though they were simply another finesse of legal or administrative thinking. In order that lawyers, as well as legislators and administrators, can be truly effective, all need to be alive to the ecological dimension and its interplay with the community at large, as well as the quality of the inheritance passing to the generations to come.

\section{IMPLICATIONS OF GLOBAL CLIMATE CHANGE}

Wolfgang Sachs' lecture was directed at the need to address fundamentals rather than treat symptoms, the importance of effecting positive change and avoiding reliance on risk management and systems engineering. He dwelt specifically on the far-reaching implications of climate change, emphasising the fact that none of us is likely to be immune from its consequences. From the perspective of those in the Northern Hemisphere, the impact of global warming is thought of as a problem for those primarily in the southern regions of a subtropical nature. It is there that a variety of catastrophes occur, whether through increased flooding and the submerging of islands at one end of the scale or, at the other, the extremities of water shortage and ravages of drought. All that is seen as far removed from us: the warmer summers in Britain could even be an attraction, no matter that there may be the occasional downpour of equatorial-type rain or at other times extended periods of water shortage.

The lesson drawn by Wolfgang Sachs, however, is that such a seismic change will carry with it the transition of the northern temperate zone to one more akin to that of the southern and the creation of habitat and conditions in Europe hitherto more likely to be found in Africa and India. With this will come the prospect of insect-born illnesses spreading northwards and, as the temperature increases, 'the day of the mosquito' will be said to have arrived!

Within that global setting, how we respond to change, the manner in which we assess our needs and honour our obligations to the coming generations will come into harsh relief. Reactive steps, because of the very nature of the problem, will be too late; it is the proactive approach for which we need to be equipped. With that in mind I advance four propositions:

(1) The law is not an end in itself but must be, and be seen to be, connected with all aspects of life. To provide an effective framework within which environmental considerations are suitably provided for, the legislators who frame the laws, the judiciary who interpret them and the practitioners who are foot soldiers in the front line, must recognise and deal with such needs in these holistic terms.

(2) Whereas we in the UK - or rather England, as perhaps we should exclude Scotland and Wales with their separate planning and administrative processes - alone cannot make all the difference we can make some difference and, by example, encourage others.

(3) Changes are afoot in standards and proposals coming from the European Commission which we should embrace willingly and actively now, rather than wait to be dragged into an apparently reluctant acceptance of them. We should also view the incorporation of the European Convention for the protection of human rights and fundamental freedoms (ECHR) into our statute law as an opportunity, bringing with it, as it does, the experience and findings of the European Court of Human Rights.

(4) Finally, it is in our interest - a simple matter of self-interest - to recognise the trends, implications, consequences and disadvantages of further environmental degradation and ensure that effective steps and machinery are in place to counter this. 


\section{PRESENT JURISPRUDENTIAL ASSUMPTIONS}

Against that background, I start with the proposition that a number of legal assumptions and administrative procedures that we hold dear appear to be revered more for the length of time for which they have survived than for their continuing contribution to the effective rule of law and their relevance to sustainability. The legal machinery now in place often militates against the environmental dimension and, recalling a line from the '60s (Marshall McLuhan, I believe), the message can be said to be found in the medium through which the law functions. This is apparent from the number of institutions we maintain and the levels of inbuilt standards and parameters that constitute the established, and thereby assumed, norms - which by their very nature perpetuate those norms. If we settle for a regulatory approach, and an administrative and judicial line which places the environmental aspect in a subsidiary role to other matters, be they fiscal or the mindset of what the essentials of life in the 21 st century comprise, then that predetermined mechanism, the medium through which the environment is governed, conveys the message very clearly - namely that environmental concerns do not have the degree of priority which government is keen to claim. In short the basic assumptions from which we operate govern the laws that are ultimately put in place.

We therefore need to look critically at fundamentals and test whether, on turning over a number of the bedrocks of our jurisprudential assumptions, they stand the test of time and remain as relevant and appropriate now as when they were first put in place. In this I would identify within the space available: land use and property rights; planning and public law; civil and criminal liability with related requirements as to evidence and procedure; and finally corporate governance and responsibility.

\section{Land use and property rights}

The use of property was historically related to the rights and entitlements of estate owners and only subsequently to obligations. In many respects the law relating to property ownership reflects the social history of England. Establishment of any regulatory regime for planning did not warrant legislative attention until the beginning of the last century, namely the 1909 Housing, Town Planning Act. Even that was primarily directed towards 'securing proper sanitary conditions' for new housing, but it did at least give local authorities power to determine how land should best be used.

It was the Town and Country Planning Act 1947 that set the standards against which future legislation evolved, continuing through the latter half of the 20th century, and by which a number of ancillary agencies have arisen. Built into the regime, however, is the underlying presumption in favour of development, so that that is the norm and limitations or objections are, no matter how described, not the norm. The current byword of course is sustainable development, as distinct from any old development - but it is development nevertheless! That in itself may not be objectionable: what is questionable however is the authority given into the hands of the Secretary of State for the Environment, Transport and the Regions to exercise all statutory powers other than those delegated to planning authorities, with overriding responsibility for land use and transportation, as well as adjudicating on planning appeals. The question is whether that amalgam of activity is really appropriate to the 21 st century, whether this medium really gives, indeed is capable of giving out, the environmental message to which, in principle at least, this and the preceding government have expressed commitment.

To have one government department seeking to satisfy all demands is not satisfactory. The tension between being supportive of development (albeit with the imposition of preconditions) on the one hand, and the precautionary argument that favours conservation on the other, is very real. The perceived short-term gain often masks longer-term disadvantage: the benefit accruing to one part of the country for the siting of a particular development could well be at the expense of another and strains on infrastructure are not always fully anticipated.

\section{INTERPLAY}

the law, and those who make and practice the law, cannot approach environmental issues in isolation ... all need to be alive to the ecological dimension and its interplay with the community at large, as well as the quality of the inheritance passing to the generations to come.

The primary resource of this country is in its land, the urban as well as rural environment, natural habitats, wildlife such as remains, the open countryside, forests, waterways, seas and the air we breathe and by which we have our very existence. The mantra of 'sustainable development' frequently results in the application of tests, which, if not contradictory, are naive at best and specious at worst, in an endeavour to bridge the gap between what are often fundamental opposites.

A recent European Commission White Paper emphasises the need to work by way of steps that are precautionary, proportionate and preventive ('the three Ps') and, to complete the alliterative process, it re-emphasises the polluter-pays principle. It is unrealistic to expect that these aims can be fulfilled within the current planning process, imposing as it does still further contradictions between the stance taken by the EC and how the Department of the Environment, Transport and the Regions (DETR) sees its own role. A separate, governmentfunded department, expertly serviced, has at least the prospect of ensuring that the 'three Ps' principle is fully explored and given the level of significance it warrants. New Zealand has established a Department of Conservation as a governmentresourced agency. Put into effect here, such an agency would result in a better balance being seen to be at work, we should benefit from a more imaginative use of the doctrines of precaution and prevention and have to place less reliance on the polluter paying after the event.

An instance of this two-horse riding is in the planning appeals process itself. In the main, appeals are handled by an inspector appointed by and reporting to the self-same secretary of state. On standing back and disengaging from a system that, because of the length of time it has been in place takes on an almost theological authority, it must be seen as a curiosity, and a strange approach to a system that has an inbuilt capacity inevitably to create conflict of interest and is emphatically out of step with a concept of justice that favours the need for it to be seen to be done.

The DETR is now reviewing ways and means of simplifying appeals procedures and thus enabling the process to be speeded 
up: while not directly akin to the government's proposals for limiting the right to trial by jury, and the reduction in legal aid, the current proposal to limit and reduce the right to public enquiries smacks of that philosophical vent. The Treasury ought not to be the arbiter on matters of justice. As I shall suggest later it would wholly be in keeping with the creation of an environmental court system for the Inspectorate to be responsible to that authority rather than to a government department.

If that proposition is considered overly radical, the next no doubt will be seen as a heresy. It relates to the entitlement of third parties to appeal against a grant of planning approval. Again, it is a curious assumption that a developer should be entitled to challenge the finding of a planning authority against a refusal, while those who live and have homes in the vicinity and are most affected have no right of appeal against an approval regarded locally as undesirable. In part this novel approach stems from the initial presumption that the primary duty of a planning authority is to regulate development rather than to prevent it. Supporters of the status quo argue that such a change would impede the flow and pace of development and prove unacceptable to the building industry. The Republic of Ireland however allows third party appeals - and that in a country where over the last decade there has been a huge swell of development. According to Professor Malcolm Grant third party appeals there make up over 40 per cent of all planning appeals and are having some slowing effect upon development.

The proposition that the local planning authority may be assumed to have taken full account of all local factors and priorities in granting its consent to develop and that local people therefore can safely leave such matters in its hands is unfortunately not supported on the ground. Statistics collected over the past eight years by the Environmental Law Foundation identify land use issues and dissatisfaction with local planning authority decisions as constituting a major number of the complaints it handles, accounting for some $40 \%$ of referred cases to it in the year 1998/99.

The ECHR, as incorporated in the UK's Human Rights Act 1998, has particular relevance here. Article 2 guarantees life while art. 8 specifies 'respect' for private family life and home; beyond that, art. 6 relates to a fair trial in 'the determination of civil rights'. Whether taken separately or in combination there is enough there to support a challenge by local objectors to a planning consent on the grounds that it breaches the rights of local people to preserve their way of life.

These prospects lead all the more to the conclusion that the setting up of environmental courts in the Australian style, or at the very least an environmental division of the High Court akin to the Company Courts or Family Division, is increasingly appropriate. Lord Woolf introduced the possibility in 1991; the Labour Party in opposition were in favour and now Professor Grant has issued his report to the DETR on similar lines.

\section{Civil and criminal liability}

It is well established and accepted that ownership of land carries responsibilities. More needs to be made of its obligations and limitations as well as rights. The most significant regime coming into play as from 1 April 2000 comprises the statutory guidance relating to land contamination and the various mechanisms this has introduced. Again there is a mixture of checks and balances, with commercial considerations at one end of the scale and the broader community needs and long-term implications on the other. The EC perspective on environmental liability is the recognition that environmental damage goes beyond that of injury to the person or simple, direct property damage. The EC proposal incorporates the need for full restoration of what has been damaged, while recognising that such a possibility does not always exist, either because the damage is too far advanced or the responsible parties are without funds. If we are serious about preservation and conservation then the sites of contamination must have their reinstatement funded at state level.

Accompanying the setting of standards and defining of liability is the practical matter of the ability of citizens to argue their case and seek remedies. This is part of the greater question of access to justice, coupled with which is the need to alleviate restrictions on legal standing built into our system. As things stand, there is an acceptance by the courts that established NGOs such as Greenpeace and Friends of the Earth have a special place in the matter of standing. It remains difficult, however, for citizens' groups got together to face a particular problem in their own locality to be so readily recognised. This is a total incongruity, denying the very people most affected, who, having established a sensible working group, are unable to have their association seek redress through the courts. We have yet to see whether the 'victim test' expressed in art. 34 of the ECHR, as incorporated expressly by HRA, s. 7(7), has the effect of extending the standing rights by reason of the 'sufficient interest test'.

The special and distinctive characteristic of the environment is that the issues engaged affect not only those of today but those many more of tomorrow. That presents a unique legal challenge, demonstrating it to be a special case that warrants a dedicated forum as well as procedural rules that take full account of this fact. On the matter of standing, we should welcome a recent decision of the Supreme Court of the Philippines whereby lawyers instructed by an organisation formed in the name of the generations not yet born, but who will inherit the land, were approved as representing clients with locus standi and entitled to represent the case for those 'clients', even though they were not identified or indeed identifiable! This has the making of a test case waiting to happen here!

This concept was focused on by the Fourth Ministerial Conference in Aarhus, Denmark, in June 1998 (to which the UK Government was a signatory). It recommended better access to the courts for individuals who can demonstrate an interest in the issues in hand, as well as by established NGOs. What was not provided for, however, was the cost of proceedings, the question of funding and the difficulties local people have in arguing their corner in a telling and effective manner. The Environmental Law Foundation (ELF), of which I am co-founder, has played an important role in this respect. Since its formation in January 1992 the charity, through a network of practitioners comprising lawyers and other experts, has offered support and representation to local community or neighbourhood groups in over 1000 cases, providing an initial pro bono appraisal and thereafter continuing professional support at low legal aid rates of charging. That comprises 1000 
local incidents and problems that might otherwise not have been argued or adequately presented.

The seeking for consistency, the insights required and the particular nature of these special cases, all point to the desirability of establishing separate environmental courts. Even without the creation of such institutions, much would be gained if there were 'Woolf Two', in which court procedure was specifically re-constituted in cases involving an environmental issue. It will necessitate a rethink on the burden of proof, enabling a shift requiring the defendant, once a prima facie case is established, to demonstrate that the nuisance, negligence or damage complained of does not emanate from his/its source. This would need to be dealt with in conjunction with a realistic approach to the strict causation test, leaning towards the balance of probability on the evidence placed before the court. Beyond that, the traditional adversarial stance does not always suit issues of an environmental nature, where the court should have the benefit of its own experts rather than placing experts in adversarial contention. It may be that there are tolerances in opinion on particular points, but those can be presented as an agreed statement of views rather than as conflict between two competing parties.

\section{ETHICS AND ECONOMICS}

however reluctant the government may be to impose fresh regulatory requirements upon companies and their directors, there is the beginning of a ground swell in favour of corporate activity with greater social responsibility. By ensuring evenhandedness through legislative intervention we avoid the risk that one company might be disadvantaged by another.

On the matter of reversal of the burden of proof, it is in a way a logical extension of the doctrine of res ipsa loquitur. Beyond that, art. 8(1) of the ECHR provides for qualified exceptions to the right to a home and private life in which interference by the state must be shown to be necessary and proportionate. As a consequence, the state or public authority has to justify its reliance on the exception and has to discharge that obligation as a pre-condition of proceeding. In short, the onus in such cases is upon the plaintiff or prosecution. It will be noted that whereas domestic disputes between private individuals are not directly subject to the ECHR, our distinguished Lord Chancellor has urged the courts that there should be compatibility between methods of dealing with private disputes and those of a public law nature.

A further indicator is in the European Commission's recommendation for tightening the law in regard to product liability by reversal of the burden of proof. Once a prima facie case has established that defects exist and damage has been suffered, the victim will not be required to establish the causal link. It is for the manufacturer to demonstrate that there is a non-linkage. Other proposals involve full disclosure of company records and procedural points that will ease the path of the plaintiff.

This is all very much in keeping with the 1998 Aarhus Convention, which presupposes the provision of updated environmental information by local authorities and its dissemination to the public at large. The implementation of such requirements as set out in the Freedom of Information Bill, however, falls short of this open approach.

Another recommendation published by the European Commission at the end of 1998 urges member states to introduce minimum criteria for what are described as 'environmental inspections'. Its aim is to establish in each country effective mechanisms for monitoring the performance of environmental legislation and to ensure that EC directives are being properly implemented. The theme is that all member states must (subject to the acceptance of subsidiarity) comply with agreed regulations and procedures so that the systems of inspection and enforcement will be subject to greater harmonisation and be more in evidence. Guidelines are put forward for this purpose. The Contaminated Land Guidelines issued by the DETR provide for something of this in their inspection processes, but a limiting factor is in the resources made available for adequate implementation. The UK Environment Agency has certain powers but most are of a reactive nature rather than following the proactive line contained in the EC recommendation.

Throughout, the EC emphasis is on greater participation by the community and on the need to ensure that communities have access to all relevant information and the opportunity to express their views. Against that philosophy we now have the situation in which assembly for purposes of protest comes within the remit of the criminal law. Whether this is compatible with art. 11, ECHR, which deals with freedom of assembly and association, doubtless falls to be tested.

It simply does not do to frame laws and preserve a system that fly in the face of what is palpably the more enlightened view emanating from the EC. The precautionary principle would oblige us to take account of the hidden costs involved in authorising development or approving industrial processes. Those that are hidden often relate to what falls upon the public purse or on public health, such as the BSE consequences and the GM foods affair. These 'knock-on' effects and clean-up processes are simply not brought adequately into account. The cost benefit analysis built into the Contaminated Land Guidelines is an example of ignoring such matters.

All of these ideas will help reshape issues of liability and the means of dealing with pollution and its consequences in its various forms.

\section{Corporate governance and responsibility}

A further issue is the need to hold the directors and management of corporations personally liable where breaches involve matters of criminality. Every corporate summons alleging breach of regulations should include the board and its managers, unless they can demonstrate not only that they were not responsible but there were others of an appropriate competence dedicated to oversee the matter in hand and that all reasonable steps had been taken to establish an appropriate regime. For this purpose we need to see a reduction in the legal escape routes that a company vehicle may introduce for the avoidance of personal ability.

The separate legal identity of companies has undoubtedly been of considerable importance in the commercial development of this country. Nevertheless, the separation of the 
company entity from its shareholders and the protection of limited liability for the conduct of directors has been gradually eroded over time, exposing directors to personal pursuit in certain instances in matters of a fiscal nature: in cases of insolvency or in relation to tax, national insurance and excise duty obligations. There is certainly power in the hands of regulators now to include directors and managers where there is a regulatory breach that triggers criminal charges. While there have been many summonses brought against companies, however, there are relatively few involving directors and managers.

It would serve as a salutary warning to others to take a more direct interest and active part in safeguarding and monitoring the environmental dimension if the regulators, including the Environment Agency, were more assertive in this regard. According to the agency, one of the reasons for the relatively few personal prosecutions is the difficulty in establishing who among the board of directors or the board of management is actually responsible. In my view if a company is so run, then the whole board must be deemed responsible and suitably dealt with.

There are other aspects to the implications of corporate 'separateness'. Even before the proliferation of industrial globalisation, parent companies situated in one jurisdiction were very reasonably setting up subsidiary companies in jurisdictions local to wherever the industrial or other activity was engaged. As environmental awareness has increased, regulations have come into being and standards been applied in the UK and elsewhere in the EU which, while binding on the parent companies formed and operated within the UK or other parts of the EU, have not impacted upon the manner in which subsidiary companies, often in third-world countries, are operating. The question is before the courts at the moment, namely the extent to which third world citizens employed by the local subsidiary of a UK company are entitled to seek redress in the UK courts. If one accepts the obligation and responsibility for proper management of the parent company, it is hard to see why a lesser obligation should exist in respect of a subsidiary company, particularly where it contributes to the profit of the parent company and benefits shareholders by way of improved dividend, as well as directors by way of increased salary!

A review has been initiated by the DTI in regard to changes in company law, among which directors' duties to shareholders are coming under scrutiny, together with the question of whether these should be qualified to take account of and avoid company activities that are to the detriment of the local community or others who may be affected by its activities. The principle of enlightened shareholder value is being talked of; there are practical difficulties of definition and compatibility in resolving these matters but the fact that it is seen as a topic for serious debate is impressive in itself.

All of this is part of rethinking corporate governance and its place in social responsibility. The Friends of the Earth report, 'Pollution in Justice', identified that $90 \%$ of the biggest polluting factories are in the poorest parts of the country, a fact which prompted Charles Secrett, Director of Friends of the Earth, to comment that environmental issues are about public health and social justice. There are signs that companies are responding to the ethical demands of investors and to the recognition that providing information on their social and environmental performance in conjunction with financial results demonstrates sound business management within the hierarchy of corporate standing.

There is also financial pressure from banks and pension funds who want to ensure that the operation of a company does not result in the accumulation of financial liability. Additionally, auditors want to be certain that any failure to insist upon reserves or notes on account will not put them at risk of subsequent claims in the event of future takeovers, etc. It was reported in the Financial Times in January this year that the Ford Motor Company has withdrawn from the Global Climate Coalition, whose primary purpose is to dispute the risk of global warning and resist the imposition of government action to curb carbon emissions. Their action follows that of the major conglomerates Shell and BP, who have joined the Business Environmental Leadership Council in which there are 21 large companies committed to pressing the American Congress for action on carbon emissions.

The interesting point is that the companies themselves see this not only as ethical thinking but also as good economics. My point is that however reluctant the government may be to impose fresh regulatory requirements upon companies and their directors, there is the beginning of a ground swell in favour of corporate activity with greater social responsibility. By ensuring even-handedness through legislative intervention we avoid the risk that one company might be disadvantaged by another.

\section{CONCLUSION}

Within the space available I have not been able to dwell adequately upon the impact of public opinion ('people's power') - as demonstrated most dramatically in the last 18 months in the attitude towards genetically modified organisms, how market forces can be so dramatically affected by public opinion and where government policy has failed to keep pace with that opinion.

My urging is that rather than being dragged, reluctant and protesting, into the 21 st century, the legislature should voluntarily embrace substantive changes that will aid and support environmental sustainability. Sir Crispin Tickell, in a lecture last year to the Royal Institute of International Affairs on the imperfections of the World Trade Organisation, introduced the dictum that:

\section{the economy is a wholly-owned subsidiary of the environment'}

I find this seductive thinking and commend it with the complementary thought that the law can be, and should be, the handmaiden of environmental protection. I urge the adoption of such an approach as an essential motivation within the new resolve needed to meet the challenges of this new century.

\section{Martin Polden}

Head of Environment Unit, Ross \& Craig; member of Law Society Planning and Environment Committee; Co-founder and current President, Environmental Law Society

Martin Polden is joint author of 'The Environment and the Law', taking the theme of earth, air, fire and water.

This article is based on a lecture given to the Society for Advanced Legal Studies in January 2000. 